\title{
Economics
}

\section{Estimation of Supply Response of Livestock Products: The Case of Kajiado District}

\author{
Manyeki John Kibara ${ }^{1}$, Ruigu George ${ }^{2}$, Mumma Gerald ${ }^{2}$ \\ ${ }^{1}$ Section of Socioeconomics and Biometric, Kenya Agricultural and Livestock Research Organization, Arid and Rangeland Research \\ Institute - Kiboko, Makindu, Kenya \\ ${ }^{2}$ School of Economics, University of Nairobi, Nairobi, Kenya
}

Email address:

manyekijk@yahoo.com (M. J. Kibara),mwathi45@yahoo.com (R. George)

\section{To cite this article:}

Manyeki John Kibara, Ruigu George, Mumma Gerald. Estimation of Supply Response of Livestock Products: The Case of Kajiado District. Economics. Vol. 5, No. 1, 2016, pp. 8-14. doi: 10.11648/j.eco.20160501.12

\begin{abstract}
During early 1970s and early 1980s economic conditions in general had been favourable for the Kenyan farm sector. Following market liberalization in the late 1980s, farmers and in particular livestock farmers experienced economic hardship. The economic situation facing livestock industry was characterized by wide fluctuation and unpredictability of the livestock and livestock product prices and uncertainity in livestock production and marketing. These shocks coupled with economic conditions in the livestock sector rendered profit-oriented decision-making by livestock farmers and other participants in the industry difficult. The objective of this study was therefore to estimate the livestock products supply responses using an error correction method. The estimators of the model were derived by way of regression and correlation after subjecting the data collected to vigorous testing for stationarity using Augmented Dick-Fuller test. Conclusions were made on the basis of R2 (coefficient of determination) as well as the $\mathrm{t}$ statistic. The results indicate that the estimated short run supply function, live cattle and cattle hides were price elastic while sheep and goats were inelastic. The long run supply response was positive although inelastic for live cattle and goats while cattle hide was elastic. The results also showed positive short run price elasticity. On the basis of t-value, the findings were conclusive with all the variables analyzed being statistically significant. The study also found that live cattle and cattle hide supply adjust to equilibrium levels quite fast. These results suggest that livestock farmers in the study area adjust their supply quiet early, probably as soon as they gain the slightest indications that the market signal would be permanent.
\end{abstract}

Keywords: Error Correction Model, Livestock Products, Long Run, Short Run, Price Elasticity, Supply Response

\section{Introduction}

Livestock production plays an important role in the Kenyan economy. It is one of the sectors with the greatest potential to contribute to poverty reduction through its wide range of activities. There are large and diverse populations of livestock in Kenya used for food, income generation, draught power and socio-cultural functions [1, 2]. In the year 2002, the livestock sector contributed $10 \%$ of the national gross domestic product (GDP) and about 30\% of the agricultural GDP, which in turn contributed about $25 \%$ of the national GDP. In the same year the livestock sector employed $50 \%$ of the agricultural labour force and provided substantial raw materials for local dairy, meat and meat processing industries, as well as, hides and skins for tanneries [3, 4].

The production of livestock and livestock products in Kenya face: high price variability and unpredictability.
Uncertainty in the livestock production and marketing exists with respect to the future. Because of inadequate production planning, there is a mismatch between the supply and demand for livestock and livestock products 1 [1]. These shocks are associated with high livestock marketing transaction costs emanating from a number of factors which include threat from frequent droughts, poor marketing and communication infrastructure for livestock and livestock products, disease outbreaks, insecurity and high costs of trekking livestock to markets. High levels of inbreeding lead to low levels of productivity. In addition, there is a lack of

\footnotetext{
1 This is because the projected output for beef in year 2000 was 322,000 metric tonnes whereas the demand was 336,000 metric tonnes showing a deficit of 14 , 0000 metric tonnes, the projected output for mutton the same year was 81,000 metric tonnes and demand was 87,000 metric tonnes showing a deficit of 6,000 metric tonnes, the projected output wool was 2,500,000 metric tonnes and demand was $2,700,000$ metric tonnes showing a deficit of about 200,000 metric tonnes.
} 
pro-pastoral policy environment [5]. Market uncertainty in pastoral areas also arose following the collapse of Kenya Meat Commission (KMC) which used to be the buyer of last resort.

The lack of a transparent, timely and efficient marketing infrastructure for livestock and livestock products was recognized as a major factor hindering the improvement of gains that accrue to the pastoralists [6]. The economic liberalization of 1987 has also contributed to these macroeconomic shocks and greater market price variability and unpredictability for livestock and livestock products. The marketing of livestock and livestock products currently is conducted on an ad hoc basis with pastoralists, middlemen and butchers playing a major role. The risk mapping study [7] stated that pastoralists themselves consider the prevailing livestock markets, especially the prices which they receive for their products to be the major source of the risk which they faced. Consequently, livestock marketing remains one of the greatest challenges in the development of the livestock industry in Kenya. In spite of the current emergence of organized market intelligence, particularly in relation to prices at the terminal market, lack of price information in many of the pastoral areas remains a critical concern for producers, traders and policy makers.

The supply response of livestock producers is a critical component of the study of livestock markets in Kenyan Arid and Semi Arid Lands (ASALs) [8]. This is because orderly marketing depends on a predictable response by buyers and sellers to different economic conditions. This study seeks to evaluate the responsiveness of livestock farmers to changes in incentives by estimating livestock products supply function. This was because there was a need for livestock farmers and policy-makers to be able to anticipate not only when prices would peak or decline, but also how prices would rise and how they would fall. The need was reinforced by the fact that it takes a relatively long time for livestock, especially cattle, sheep and goat to reproduce and grow.

It is a common belief by pastoralists and policy-makers that the primary cause of food entitlement failures is the unpredictable weather pattern in the pastoral areas. However, micro-economic conditions such as prices of livestock and livestock products, costs of factors inputs, producer and consumer behaviours and individual welfare plays an important role in influencing the quantities of livestock and livestock supplied and demanded. Microeconomic study analyzes market failure, where markets fail to produce efficient results, as well as, describing the theoretical conditions needed for perfect completion. Equally important are the macro-economic conditions such as inflation, trade, exchange rate, overall GDP growth rate, monetary and fiscal policies, risk and uncertainty and conflicts, especially during election year. It is also important to know the effect of these macroeconomics variables to the supply and demand of livestock and livestock products. This is because they affect the terms of trade between market players and the value of assets liquidated by pastoralists in hard times.

Since it requires length of time for livestock to grow and reproduce, then it results in an inevitable lag in the response to changes in the incentives. This study aimed at estimating the livestock products supply response to changes in price of livestock products, the rate of national inflation in the macro-economic environment, drought and the amount of rainfall received in old Kajiado districts. By using log-log supply response to the influencing variables, a better understanding of both the biological production path and the economic environment of the livestock industry was obtained. This kind of analysis was of great value to the decision-makers since any policy measure taken should know the resulting consequences in the supply response both in the short-run and in long-run time span. The objective of the study was to estimate the livestock products supply responses using error correction method.

\section{Methodology}

\subsection{Characteristic of the Study Site}

This study took place in the old Kajiado district. The district is found in southern rangelands of Kenya. The major characteristic of the district is that it is generally hot and dry, with low and erratic rainfall that varies widely across space and over time [9] with some pockets being warm and wet. The general topography of Kajiado district is characterized by plains and occasional volcanic hills. The land rises from about $500 \mathrm{~m}$ above sea level around Lake Magadi to about 2,500 $\mathrm{m}$ above sea level in the Ngong Hills area [10]. The rainfall is bimodal with mean annual rainfall ranging from 300 to $800 \mathrm{~mm}$, and only $8 \%$ of its land has some potential for cropping [11]. Savannah grasslands dominate the area. Livestock and wildlife co-exist in much of this area, with several major National Parks (Nairobi, Amboselli and Tsavo) bordering or falling within the district. The area is inhabited mainly by Maasai pastoralists whose livelihood depends heavily on livestock. Although semi-nomadic pastoralism, practiced on communally-owned land, has been the traditional Maasai mode of life, this lifestyle has undergone changes due to on-going land adjudication and sub-division of group ranches, progressively leading to individual land tenure system [10]. This has increased the rate of land sales thus opening the district to immigration of communities from other parts of the country, especially in the relatively high agricultural potential areas of the district for farming. Therefore, livestock production is on the decline as a considerable number of people adopt an agro-pastoral lifestyle. The growing commercialization of the pastoral economy has encouraged livestock production for the market rather than for pure subsistence. The major livestock types are cattle, sheep and goats - though the donkey has always been popular as a means of transport in this area and draft power.

According to the various reports, about $90 \%$ of the total cattle are found in Narok and Kajiado districts implying that livestock production still plays a bigger role over crops in ensuring household food security in these areas $[12,13,14]$. 


\subsection{The Supply Model for Livestock Products}

\subsubsection{Theoretical Framework}

The supply function of a firm that sells in a perfectly competitive product market gives the quantity that it will produce as a function of product price. In perfectly competitive factor markets, the quantity supplied is also a function of factor prices. A profit-maximizing firm's supply function can be derived from the first-order conditions for profit maximization. The supply curve of the firm may be derived by the points of intersection of its marginal cost (MC) curve with successive demand curves. The supply function is the inverse of the $\mathrm{MC}$ function when $\mathrm{MC}$ is equated with produce price [15]. Under the assumption of perfect competition in the product market and perfect competition in the factor markets, the theoretical framework of supply function can be derived as follows;

$$
\operatorname{Max} \pi=p y-\bar{c}(\mathbf{w}, y)
$$

Where,

$\pi=$ the profit the firm receives,

$\mathrm{p}=$ the livestock product prices,

$y=$ the quantity of livestock products supplied and

$\mathbf{w}=$ the factors prices.

The first order conditions for profit-maximizing firm are as follows

$$
\frac{d \pi}{d y}=p-\frac{\partial \bar{c}(\mathbf{w}, y)}{\partial y}=p-M C(y) \leq 0, y \geq 0
$$

If production is profitable, then the relevant part of 2 may be written as follows,

$$
p=M C(y)=\frac{\partial \bar{c}(\mathbf{w}, y)}{\partial y}
$$

Which implies $\mathrm{p}=\mathrm{MC}(\mathrm{y})$. This is the short run supply curve at some fixed levels of factor prices. $d \pi / d y$ is used to emphasize that there is only one first-order condition of concern. Since, the marginal cost is a function of $y$, equation 3 is solved for the following inverse supply function:

$$
y^{*}=y^{*}(p, \mathbf{w})=M C^{-1}(p)
$$

Where $M C^{-1}(p)$ is the inverse of the marginal cost function. The presence of fixed factors in the short run makes it likely that marginal cost increases with the level of output. If $\mathrm{p}<\mathrm{MC}(\mathrm{y})$ for all y exceeding some positive level of output, then equation 3 will possess a unique solution. The necessary and sufficient condition for $\mathrm{MC}(\mathrm{y})$ to satisfy these requirements is that $f(\cdot)$ be strictly concave in variable inputs alone. In that case, $y^{*}$ will be unique. But the entire range of the marginal cost function is not a firm's supply function. This is because satisfaction of the first-order conditions at a point where $\mathrm{MC}$ is below average variable cost (AVC) does not satisfy the total condition. Thus, a firm's supply function is given by the disjointed function:

$$
y^{*}=\left\{\begin{array}{l}
y^{*}(p, \mathbf{w}) \mathbf{f} \quad p \geq \operatorname{minimum} A V C \\
0 \text { for } p<\operatorname{minimum} A V C
\end{array}\right.
$$

\subsubsection{Model Specification}

A number of statistical techniques that are available in the literature have been used to model the lagged response while estimating the supply response functions for various livestock products. Most of the previous studies applied Nerlovian model [16], which specified output as a dynamic function of the expected price, output adjustment and some other exogenous variables with minor modification $[17,18,19,20$, 21]. Most of these models suffer serial correlation problem, causing Ordinary Least Square (OLS) estimates to be biased. Therefore, these models failed to capture the effect of macroeconomic factors which significantly influence the supply and demand of livestock production system.

Lagged values of the variables are important explanatory variables in most economic relationships, because economic behaviour in any one period is to a great extent determined by the past experience and the past pattern in behaviour. The polynomial distributed lag model allows a great degree of flexibility to capture this type of phenomenon. This model was originally suggested by Almon in 1965 [22]. Almon polynomial price lag method does not reduce the number of observations that are lost due to the presence of lagged variables; however, it reduces the number of parameters to be estimated [23]. The conceptual model in this study was designed to illuminate the relationships between quantity of livestock products supplied on their prices, political, environmental and economic variables which affect livestock production in Kenyan ASALs. This study specified the following general livestock product supply function:

$$
Y_{i t}=f\left(P L P_{i t}, R_{t}, I N F L_{t} D_{t}\right)
$$

Where, $i$ is the sample size $(i=1,2, \ldots, n), t$ is the length of time-series in years $(\mathrm{t}=1,2, ., \mathrm{T}), \mathrm{Y}$ is the quantity of livestock products supplied for sale in kilograms by a profit-maximizing livestock farmer, PLP is the price of livestock product, $\mathrm{R}$ is the amount of rainfall received in old Kajiado districts, INFL is the rate of inflation in the macro-economic environment and $D$ is the dummy variable to capture the effect of drought where,

$\mathrm{Dt}=0$ if observed year is a drought

$\mathrm{Dt}=1$ if observed $\mathrm{t}$ is a good climate

The econometric model of this specific form was specified as follows:

$$
Y_{i t}=\beta_{0}+\beta_{1} P_{i t}+\beta_{2} R_{t}+\beta_{3} \Pi_{t}+\alpha_{1} D_{t}+\varepsilon_{i t}
$$

Where, $Y_{i t}$ is the desired quantity of livestock product $i$ to be supplied at time t, $P_{i t}$ is the expected price of product $\mathrm{i}$ at time $\mathrm{t}$, is the intercept, $\beta_{1}, \beta_{2}$ and $\beta_{3}$ are prices, rainfall and national inflation coefficients respectively, $\alpha_{1}$ shifting parameter coefficients and $\varepsilon_{t}=$ the long run disturbance term of the equation.

In order to estimate the supply responsiveness to the 
exogenous variables the study assumes that the above functional relationship is a log-log function; the above equation gives the estimable long run output-supply function of the following form

$$
\ln Y_{i t}=\beta_{0}+\beta_{1} \ln P_{i t}+\beta_{2} \ln R_{t}+\beta_{3} \ln \Pi_{t}+\alpha_{1} D_{t}+\varepsilon_{i t}
$$

Where $\beta_{1}$ and $\beta_{2}$ and $\beta_{3}$ are long term supply elasticities, $\alpha_{1}$ is a shifting coefficient to capture the effect of drought on supply.

The a priori expectation was that the livestock product price would be directly associated with supply, giving a positive sign for the coefficients $\beta_{1}$. Amount of rainfall received would be directly associated with quantity of livestock product supplied, giving a positive sign for the coefficient $\alpha_{1}$. There would be an indirect association between livestock products supplied and rate of inflation, giving a negative sign for the coefficient $\alpha_{2}$. For drought, one expects an inverse relationship implying an upswing of the supply for livestock products giving a negative sign for $\alpha_{3}$. In order to estimate the supply function for livestock products, it is assumed that the demand for livestock products would be high and therefore livestock farmers would still secure markets for their increased supply.

The error correction models (ECM) can now be specified in its simpler version by means of equation (8) shown above, where the long-term relationship between quantity of livestock product supplied and the explanatory variables under study is modeled. The dynamic version of the short-term for supply is shown by first differences in the expression (8), where $\lambda$ represents the disequilibrium with respect to the long term, which will be partially corrected in each period;

$$
\Delta \ln Y_{i t}=\beta_{0}+\beta \Delta \ln P_{i t}+\beta_{2} \Delta \ln R_{t}+\beta_{3} \Delta \ln \Pi_{t}+\beta_{4} D_{t}-\lambda \varepsilon_{t-1}
$$

Where $\Delta$ represent the first difference operator implying that $\Delta \ln Y_{i t}=\ln Y_{i t}-\ln Y_{i t-1} \quad ; \quad \Delta \ln P_{i t}=\ln P_{i t}-\ln P_{i t-1}$; $\Delta \ln R_{i t}=\ln R_{i t}-\ln R_{i t-1} ; \quad \Delta \ln \prod_{i t}=\ln \prod_{i t}-\ln \prod_{i t-1}$ and $\varepsilon_{i t-1}$ is the one period lagged error correction error term.

The second stage of the process of estimation corresponds to the error correction component $\mathcal{E}_{i t-1}$. This is because such a procedure would only give the short run dynamics, and there would be a loss of considerable long run information. This is equivalent to estimate the model (9) above in the form

$$
\Delta \ln Y_{i t}=\beta_{0}+\beta_{1} \Delta \ln P_{i t}+\beta_{2} \Delta \ln R_{t}+\beta_{3} \Delta \ln \Pi_{t}+\beta_{4} D_{t}+\lambda \varepsilon_{t-1}+\ell_{t}
$$

At this point there is a convergence of the entire variables and the classical assumptions for the short run error term, et were satisfied.

\subsection{Data and Data Analysis}

The study was based on time series data on the quantities produced and own prices of livestock products for the period of 32 years, from 1975 to 2007 . The annual data for this period was collected from major publications related to the livestock industry and others containing relevant data to the subject matter. The bulk of the data was obtained from the following publications: Agricultural and livestock Statistics from the Ministry of Agriculture, Livestock Development and Cooperatives and the Kenya National Bureau of Statistic, Economic Surveys, and Statistical Abstracts. The commodity groups for which price supply response was studied included sheep and goats, cattle and cattle hide supplied and their respective prices for the study period. The data on amount of rainfall received over the study period was also obtained from Kenya Meteorological Department records. Data on inflation was obtained from the Kenya Bureau of Statistics. Dummy variable was used to capture the effect of drought in the supply of livestock product. The data were transformed into logarithmic form since the relationship appeared more stable in percentage terms than in actual value except for drought (dummy) variable. Furthermore the use of logarithms enabled the investigator to derive directly the elasticity coefficients.

The supply models for livestock products were determined by regressing the livestock output supplied on the explanatory variables. Since the study used time series data, there was need to determine whether the data used were stationary or non-stationary. The most important property of a stationary process is that the auto-correlation function depends on lag alone and does not change with the time at which the function was calculated. A truly stationary (or strongly stationary) process has all higher-order moments constant including the variance and mean as opposed to non-stationary series. If one used ordinary least square (OLS) to estimate relationships of variables of non-stationary series, one is likely to have spurious results. The study used the Augmented Dickey and Fuller tests for testing unit root against the alternative of stationary [24]. All the variables were found to represent stationary time series at the 5 per cent level of significance. To illustrate with the livestock product prices, the following equation was used.

$$
\Delta \ln P_{i t}=\alpha+\lambda \ln P_{i t-1}+\mu_{i t}
$$

Where $\Delta \ln P_{t}$ is the first-difference of the time series of the livestock product prices, and the null hypothesis was set at $\lambda^{\prime} \mathrm{s}=0$. If there was a unit root problem in the data, $\lambda^{\prime} \mathrm{s}$ would be equal to zero. The results were as follows:

$$
\begin{aligned}
& \text { Cattle } \\
& \Delta \ln p_{t}=3.10-0.34 p_{t-1} \\
& \mathrm{t}=(2.85)(-2.82), \mathrm{R} 2=0.21, \mathrm{~d}=2.31 \\
& \text { Sheep and goat (Shoat) } \\
& \Delta \ln p_{t}=0.63-0.08 \ln p_{t-1} \\
& \mathrm{t}=(1.60)(-1.46), \mathrm{R} 2=0.07, \mathrm{~d}=3.02 \\
& \text { Cattle hides } \\
& \Delta \ln p_{t}=1.13-0.40 \ln p_{t-1} \\
& \mathrm{t}=(2.66)(-2.62), \mathrm{R} 2=0.19, \mathrm{~d}=2.09
\end{aligned}
$$

Since the results in above equations suggest that the error term is not autocorrelated - based on the Durbin-Watson (d) test - the stationarity of deflated prices can be proved by the 
Dickey-Fuller (DF) test, using the t-value. Since the calculated t-value in all cases are greater than the 5 percent critical (DF) value of -2.96 , the data did not demonstrate random walk.

\section{Result and Discussion}

\subsection{Long Run Estimation}

The results of the study on the supply response of livestock and livestock product on their prices and other variables are presented in this section. The long run model (8) was estimated using OLS. The log of quantity of livestock product supplied was regressed against the log of livestock product prices, amount of rainfall received in millimeters, national inflation and a shifting dummy representing the presence of drought. The results of the regression analysis are presented in table 1 .

Table 1. The long run supply response of livestock products, estimated coefficients for a linear model.

\begin{tabular}{llllll}
\hline Livestock products & $\mathbf{L n P}_{\mathbf{t}}$ & $\mathbf{L n R}_{\mathbf{t}}$ & $\mathbf{L n \Pi}_{\mathbf{t}}$ & $\mathbf{D}_{\mathbf{t}}$ & $\mathbf{R}^{2}$ \\
\hline Cattle & 0.374 & 0.131 & -0.119 & -0.444 & \multirow{2}{*}{0.40} \\
Sheep and goat & $(2.58)$ & $(0.324)$ & $(-1.09)$ & $(-1.25)$ & \\
(Shoats) & 0.201 & 0.342 & -0.0577 & -0.280 & \multirow{2}{*}{0.26} \\
Cattle hide & $(3.00)$ & $(1.20)$ & $(-0.768)$ & $(-1.13)$ & \\
& 0.783 & -0.0714 & 0.0547 & 0.00543 & \multirow{2}{*}{0.88} \\
\hline
\end{tabular}

$\mathrm{P}<0.05$, critical $\mathrm{t}=-2.96 * \mathrm{P}<0.01$, critical value $\mathrm{t}=-3.66$

Note. Parentheses are the t-value

Where $\mathrm{LnP}_{\mathrm{t}}$ represent the natural logarithm of livestock product price at time $t, \mathrm{LnR}_{\mathrm{t}}$ is the natural logarithm of amount of rainfall receives at time $\mathrm{t}, \mathrm{Ln}_{\mathrm{t}}$ is the natural logarithm of national inflation at time $t, D_{t}$ is the dummy variable that capture the effect of drought at time $t$ and $R^{2}$ is the coefficient of determination.

Based on the t-value, the long run relationship shows that all variables analyzed were statistically significant. The coefficient of prices, rainfall and inflation can be interpreted as the long run elasticities of quantity of livestock product supplied. The estimated long run elasticity of prices, rainfall and inflation for numbers of cattle supplied had the expected sign for the coefficient which were $0.374,0.131$, and -0.119 respectively. Thus, we can interpret the long run result, as, on average, an increase in live cattle selling prices by $1 \%$ will increase the numbers of cattle supplied by $0.374 \%$, while an increase in amount of rainfall received by $1 \%$ will increase numbers of cattle supplied by $0.131 \%$. In addition an increase of inflation by $1 \%$ will reduce numbers of cattle supplied by $-0.119 \%$. The presence of drought, will result to upward shift in the cattle supply function.

The estimated long run elasticity of prices, rainfall and inflation for numbers of sheep and goats supplied had the expected sign for the coefficient which were $0.201,0.342$ and -0.0577 , respectively. This can be interpreted, as, on average, an increase in the live shoats selling prices by $1 \%$ will increase the numbers of sheep and goats supplied in the market by $0.201 \%$, while an increase in amount of rainfall received will increase the numbers of shoats supplied by $0.342 \%$. In addition, an increase in national inflation by $1 \%$ will reduce the numbers of sheep and goats supplied by $0.0577 \%$. The presence of drought in the study impacted negatively on the numbers of sheep and goats supplied.

The estimated long run elasticities of prices, rainfall and inflation for quantity of cattle hide supplied had the expected positive sign for price coefficient while rainfall and inflation had the an unexpected signs. The possible explanation to this was that reduction in amount of rainfall received would result in the reduction of the natural pasture which is the major source of feeds for the Kenyan ruminants in ASALs hence increasing the death if proper strategies to mitigate the feeds shortage are not put in place. The result indicates that on average, an increase in the cattle hide selling price by $1 \%$ will increase the quantity of hides supplied by $0.78 \%$ while an increase in amount of rainfall received by $1 \%$ will reduce quantity of cattle hides supplied by $0.07 \%$. In addition an increase in national inflation by $1 \%$ will result in increased supply of cattle hides by $0.05 \%$. This is because in Kenya market for hides and skin is operated in an ad hoc basis. On the basis of coefficient of determination $\left(\mathrm{R}^{2}\right)$ the model only explains well for quantity cattle hides supplied. The result indicates that, in long run, about $88 \%$ of the quantities of cattle hides supplied are explained by the model while only $12 \%$ is not explained. In addition, about $40 \%$ and $26 \%$ of the numbers of cattle and sheep and goats supplied respectively are accounted for by the model while the rest were not.

\subsection{Short Run Estimation}

The short run model (10) was estimated using Ordinary Least Square (OLS) under the specifications of Error Correction Model. The results of the preferred model are presented in Table 2 .

Table 2. The short run supply response of livestock products, estimated coefficients for a linear model.

\begin{tabular}{lllllll}
\hline Product & $\Delta \mathbf{L n} \mathbf{P}_{\mathbf{t}}$ & $\Delta \mathbf{L n R}_{\mathbf{t}}$ & $\Delta \mathbf{L n} \mathbf{\Pi}_{\mathbf{t}}$ & $\mathbf{D}_{\mathbf{t}}$ & $\boldsymbol{\varepsilon}_{\mathbf{t}-1}$ & $\mathbf{R}^{\mathbf{2}}$ \\
\hline \multirow{2}{*}{ Cattle } & 0.70 & -0.25 & -0.03 & -0.01 & -0.78 & \multirow{2}{*}{0.73} \\
\multirow{2}{*}{ Sheep and goat } & $(4.11)$ & $(-1.88)$ & $(-0.39)$ & $(-0.04)$ & $(-4.58)^{*}$ & \\
& 0.38 & -0.000868 & 0.01 & -0.02 & -0.41 & 0 \\
& $(2.33)$ & $(-0.01)$ & $(0.12)$ & $(-0.24)$ & $(-2.62)$ & \\
Cattle hides & 0.87 & -0.11 & 0.05 & 0.08 & -0.87 & \multirow{2}{*}{0.92} \\
& $(10.6)$ & $(-1.37)$ & $(1.16)$ & $(0.90$ & $(-3.97)^{*}$ & \\
\hline
\end{tabular}

$\mathrm{P}<0.05$, critical $\mathrm{t}=-2.96$ and $* \mathrm{P}<0.01$, critical value $\mathrm{t}=-3.66$

Note. Parentheses are the t-value

The $\mathrm{t}$-values of the error correction specifications showed that all the explanatory variables analyzed were statistically significant at 1 and 5 percent level. The coefficient on the error correction term $\left(\varepsilon_{t-1}\right)$ is significant and carries the correct sign. The Error Correction Model (ECM) coefficient indicates the speed of adjustment and in this case implies a fast adjustment to the long run relationship for cattle and cattle hides while sheep and goats was low. These results suggest that on average, there was $78 \%$ and $87 \%$ adjustment in the current period $(t)$ to the disequilibrium in the previous period (t-1) for cattle and cattle hides, respectively while sheep and goats had $41 \%$ adjustment in the current period to the disequilibrium in the previous period. Livestock farmer adjusts $78 \%, 87 \%$ and $41 \%$ of their supply of 
cattle, cattle hides and sheep and goats respectively to change in short run variables when they are certain that the changes in the variables are permanent in the next period.

Price changes had a positive effect on the supply of livestock products in all cases. On average, a $1 \%$ increase in product prices would results to increased numbers of cattle and sheep and goats supplied by $0.70 \%$ and $0.38 \%$, respectively while quantity of cattle hides would increase by $0.87 \%$. In all livestock products analyzed, the amount of rainfall received showed a negative effect to the quantity supplied in short run. On average an increase in the amount of rainfall received by $1 \%$ will result to a reduction in numbers of cattle, sheep and goats and quantity of cattle hides supplied by $0.25 \%, 0.000868 \%$ and $0.11 \%$ respectively. The possible explanation to this is that it takes some time for livestock to grow for the market hence a negative short run effect. Moreover, during rainy season, there is enough pasture and therefore livestock farmers hold out their animals to restock their herds for future sale. In addition, during rainy seasons, quantity of cattle hides supplied will decrease. National inflation had a mixed effect on the supply of livestock products analyzed. The results indicate that on average, an increase in national inflation by $1 \%$ will result to a reduction in numbers of cattle sold by $0.023 \%$, while an increase in national inflation by $1 \%$ will increase numbers of shoat and quantity of cattle hides sold by $0.01 \%$ and $0.05 \%$ respectively. This is so because cattle is the major source of income of the pastoral communities, and therefore as the inflation increases, the cost of cattle production will increases and this will result in a reduction of the supply for cattle. Pastoralists will therefore increase supply of sheep and goats and cattle hides, the next alternative source of livelihood, thus the recorded positive effects. Drought had a negative effect for numbers of cattle and sheep and goats supplied. The major culprit to food entitlement failure amongst livestock farmers is the prolonged drought. The presence of drought will shift the cattle and sheep and goats supply function to the left reducing supply at all levels. On the other hand, drought had a positive effect on the supply of cattle hides. These results imply that the presence of a prolonged drought will result to an increase in the incident of cattle death which will result in an outward shift of the supply of cattle hides by 0.90 units.

On the basis of coefficient of determination $\left(\mathrm{R}^{2}\right)$ the short run error correction model explains well all the three livestock products analyzed. The result indicates that, about $73 \%, 50 \%$ and $92 \%$ of cattle and sheep and goat's off-take and quantity of cattle hides supplied respectively were explained while the rest were not accounted for.

\section{Conclusions}

The findings reveal the existence of a long run relationship between livestock product supply, livestock product prices, amount of rainfall received and national inflation. The result of the estimated model shows that price, rainfall and national inflation plays an important role in determining the supply of livestock products. The study revealed that livestock product prices remain the major determinant of the livestock product supply response. This is because the long and short run supply response to prices for the three livestock products analyzed was found to be positive. The study also revealed that some macroeconomic variable also affect livestock production in pastoral areas. For instance, national inflation was found to be a key macroeconomic variable that affect any production system which has always been ignored in the previous studies. Persistence increase in national inflation would impact negatively on the livestock production and the supply of livestock and livestock products. Prolonged drought had upward shift of both the short and long run cattle and sheep and goats' off-take and an outward shift on the supply of cattle hides. This is because the area under study is ecologically fragile to prolonged drought resulting in degradation of soil and pasture and hence to high incidence of livestock death. The end result would be the increase in the supply of cattle hides although at lower price.

Furthermore, the study also found that in general livestock products supply for the study area adjust to equilibrium levels quite fast. These results suggest that livestock farmers in the study area adjust their supply quiet early, probably as soon as they gain the slightest indications that the market signal would be permanent.

\section{References}

[1] Republic of Kenya, "National Development Plan 1997-2001: Industrial Transformation to the year 2020," Printed by Government Printer, Nairobi, Kenya, 1997.

[2] M. Odhiambo, "Review of the literature on pastoral economics and marketing," World Initiative for Sustainable Pastoralism, IUCN EARO, Kenya, 2006.

[3] Republic of Kenya, "National Development Plan 2002-2008: Effective Management for Sustainable economic Growth and poverty Reduction,”pp30. Kenya, 2002.

[4] Republic of Kenya, "Geographic Dimensions of Well-Being in Kenya. Vol. 1: Where are the Poor?" From Districts to Locations. Central Bureau of Statistics (CBS), Ministry of Planning and National Development, Central Bureau of Statistics (CBS) in collaboration with International Livestock Research Institute (ILRI). CBS and ILRI, Nairobi, Kenya, pp 164, 2003

[5] J. Omiti, and P. Irungu, "Institutional and policy issues relevant to pastoral development in Kenya," Discussion paper no. 031/2002, 2002.

[6] Y. Aklilu, "Critical issues impacting livestock trade in Kenya, Ethiopia and Sudan," Paper presented at the $10^{\text {th }}$ annual conference of Ethiopian, Ethiopia, 2002.

[7] K. Smith, C. B. Barrett, and W. B. Paul, "Participatory Risk Mapping for Targeting Research and Assistance: An application among East African pastoralists,” Mimeo, 1999.

[8] D. Bailey, C. B. Barrett, P. D. Little, and F. Chabari "Livestock markets and risk management among East African pastoralists: Areview and research agenda. GL-CRSP Pastoral Risk Management Project Technical Report No. 03/99, Utah State University, Logan, 1999, pp 46. 
[9] D. P. Kariuki, and W. Letitiya, "Livestock production and health challenges in pastoral areas, Samburu District," Kenya, Kenya Agricultural Research Institute (KARI), Nairobi, 1996.

[10] Republic of Kenya "Kajiado district Vision and Strategy: 2005-2015," Ministry in the Office of the President, pricewaterhouse coopers, Arid Lands Resources Management Project, July 2005, Kenya.

[11] S. Bekure, P. N. De Leeuw, B. E. Grandin, and P. J. H. Neate, "Maasai herding: An analysis of the livestock production system of Maasai pastoralists in eastern Kajiado District," Kenya, ILCA Systems study 4, ILCA (International Livestock Centre for Africa), Addis Ababa, Ethiopia, 1991

[12] A. W. Mukhebi, H. C. Knipscheer, and G. Sullivan, "The impact of food crop production on sustained livestock production in semi-arid regions of Kenya," Agricultural systems vol. 35(4), pp339-351, 1991.

[13] I Scoones, "The economic value of livestock in the communal areas of southern Zimbabwe," Agricultural system vol. 39(2), pp339-359, Zimbabwe, 1992.

[14] Republic of Kenya, "Livestock marketing from pastoral areas in Kenya: A Strategy for Pastoral Development," A Report by Arid Lands Resources Management Project in conjunction with SNV, OXFAM and World concern. Office of the President, Nairobi, Kenya, 2000.

[15] M. J. Osborne, "The supply functions of a profit-maximizing price-taking firm," 1997, http://www.economics.utoronto.ca/osborne/2×3/tutorial/PRO MAX.HTM.
[16] M. Nerlove, "The dynamics of supply: Estimation of farmers' response to price," Baltimore, Johns Hopkins, 1958.

[17] L. O. Ndzinge, J. M. Marsh, and R. C. Greer, "Herd inventory and slaughter supply response of Botswana beef cattle producers," Journal of Agricultural Economics, Vol. XXXV, No. 1. 1984.

[18] A Lapodini, "An econometric model of the U.S.A beef-cattle industry," A PhD dissertation in Agriculture, Texa Tech University, U.S.A. 1989.

[19] D. Aadland, "The economics of cattle supply," Working Papers 2000-11, Department of Economics, Utah State University, Logan, 2000.

[20] M. B. Dastagiri, "Demand and supply projections for livestock products in India, National Centre for Agricultural Economic and Policy Research, New Delthi, India 2004.

[21] D. M. Nyariki, "Price response of herd off-take under market liberalization in a developing cattle sector: panel analysis applied to Kenya's ranching," Environment and Development Economics: pp 1-18, Cambridge University Press, 2008.

[22] S. Almon, "The distributed lag between capital appropriations and expenditures," Econometrica, vol. 33, pp178-196, 1965.

[23] H. Kelejan, and W. E. Oates, "Introduction to Econometrics: Principles and Applications," New York: Harper and Row, Publishers, 1974.

[24] D. A. Dickey, and W. A. Fuller, "Distribution of the estimators for autoregressive time series with a unit root," Journal of the American Statistical Association, vol. 74, pp 427-431, 1979. 